\title{
From Physics Olympiads to Medical Research: Lessons Learned
}

Andres Zorrilla-Vaca'

\section{The Experience}

For the last four years I have been fully dedicated and immersed in the study of Physics. I was part of the National Colombian Team for the Physics Olympiads tournament, organized by the Antonio Nariño University for the past twenty-nine years. This great honor required intensive training sessions in Bogota, Colombia, and rigorous self-study to increase my knowledge and gain experience. With great responsibilities come not only great challenges but also important rewards. In my case, I was lucky to visit fascinating places around the world, such as TaIlinn and Tartu, Estonia, and meet interesting people who shared my love and passion for science and the field of physics. In retrospect, now one year after having finished my experience in the Olympiads, I realize the heritage that these learning experiences in physics have imparted on me: the necessary skills to perform medical research in my university.

I assumed the task of applying my investigational skills acquired in the study of physics, to the study of medicine through participation in several medical student research groups derived from the ACEMVAL - Scientific Association of Medical Stu-

About the Author: Andrés Zorrilla-Vaca is currently a second year medical student of a six-year program at the Universidad del VaIle, Cali, Colombia. During high school he received several awards in Physics olympiads, including absolute champion for Colombia and bronze medalist for Ibero-America. performance in other annual routine tests, in July 2012 I had the honor of representing my country in the 43th International Physics Olympiads (IPh0) organized in Tallinn, Estonia (Figure 1, available from: http://issuu.com/e-ope.ee/docs/ipho2012/1, updated 16 Sept 2012; cited 2013 Jan 15). At the time, I was completing my final year of high school. Because of my partici-

Figure 1. Photograph Taken During my Participation in the International Physics Olympiads, Enjoying the Estonian Capital: Tallinn.

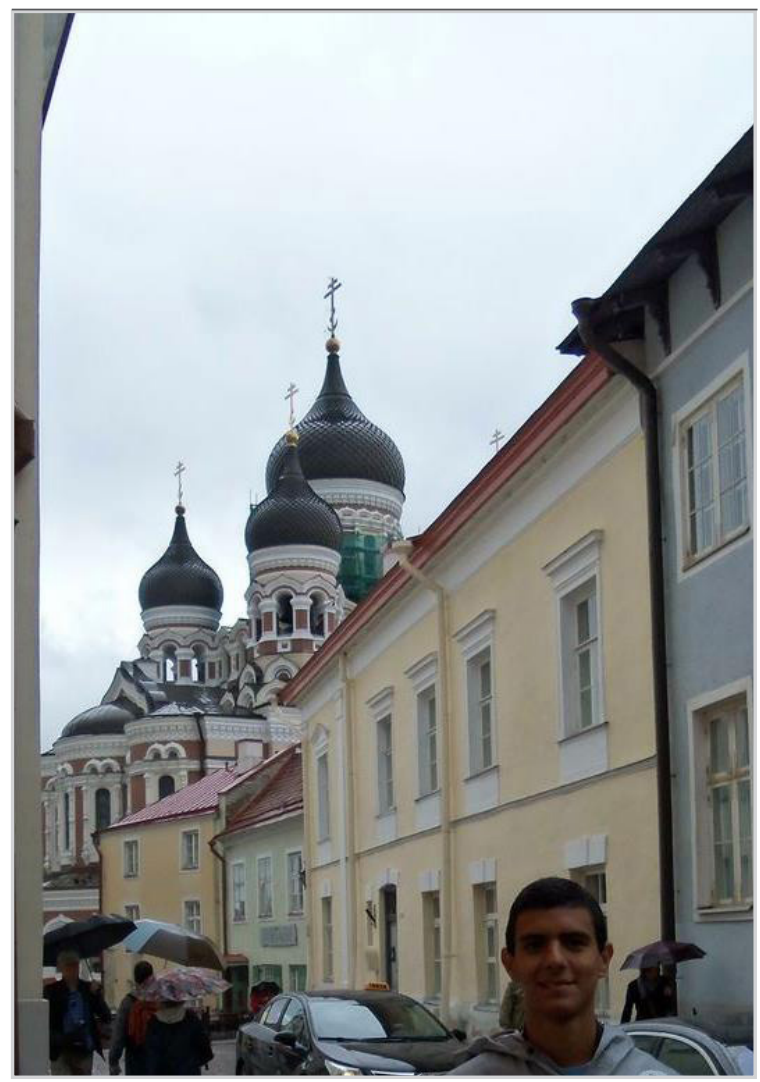
several years in the Regional Mathematics and Physics Olympiads. In 2011 I won the major distinction in the national test and in the same year I represented my country and became the bronze medalist in the $16^{\text {th }}$ Ibero-American Physics Olympiads (IbPh0). Finally, thanks to the effort, dedication and

\section{My Experience in the Physics Olympiads}

Thinking back to the days when I was starting high school, the internal competitions in mathematics and physics were the first step in the path of the Colombian Physics Olympiads. These intra-school competitions were held every year and after progression through different stages, the qualified students were invited to the regional competitions for Southwest Colombia. If successful, they would participate in the National Olympiads. At the National level, everyone would compete for the distinction of medalist, winner and absolute champion of the Colombian Physics Olympiads (CPh0).

I was honored to be among the first places in the ranking for pation in the events of Olympiads, our team got the opportunity to meet and listen to conferences by distinguished scientists. Sir. Harold Kroto, chemistry Nobel Prize, shared with us his

${ }^{1}$ Program of Medicine and Surgery, University of Valle, Cali, Colombia. 


\section{Experience}

thoughts on the chemistry of carbon and amusing life-lessons about the dreams he never fulfilled such as becoming a superhero, portraving in this way, to never lose the hope in your own personal goals (Available from: http://issuu.com/e-ope.ee/ docs/ipho_uudiskiri_no6_web/1, updated 16 Sept 2012; cited 2013 Jan 15). Another event that had a profound impact on me was the visit to the AHHAA Science Center, where we could have direct contact with amazing technological inventions and biological discoveries that in most of cases have imparted significant impact on the global community. All of these exciting cultural visits allowed me to understand the great impact that research can have in the daily routine of humanity.

\section{Parallels of the Olympiads Skills Set to Medicine} Infancy and adolescence constitute important stages for the dynamic growth of the human being. Scientific literature establishes that some fundamental aspects of these developmental phases are interaction with physical objects and its experimentation to explore new paths or alternatives.' In my experience, I grew up in an environment that fostered exploration and consequently, during high school, my principal interest was the competitions in the Physics and Mathematics Olympiads where I was able to explore and experiment with the physical world to propose solutions for problems. These skills developed a suitable platform to succeed in my future endeavor as a medical student-researcher in training.

Focusing on research, an area that was particularly promoted in the Olympiads, I could verify that the tests used in these competitions are based on experimentation. During the competitions, having a strong theoretical knowledge played a very important role, but it was the ability to develop creative solutions with strong justification that was paramount in being able to solve a problem. Furthermore, without a systematic process mistakes would filter in the competitions.

Through understanding the relationship between theoretical knowledge, experimentation, and proposing creative solutions to a problem using a systematic process, I have been able to spend my time as a medical student applying the skills I have learned in the Olympiad competitions to the field in which I wish to progress: Medicine. The experience acquired from the physics exercises prepared me to apply the rigor of the scientific method to the new hypotheses and problems that I want to start addressing in medicine. Furthermore, historically the relation between medicine and physics has been shown and clearly identified as making great contributions to the progress of medicine; for example in fields like radiology, genetics, physiology and many others. ${ }^{2}$

Now that I have started the next phase of my life in medical training, I joined a research group that focuses on Infectious Diseases. I have been able to consider the importance of my early exposure and practice of the scientific method in experimental studies and how this helps to obtain a better understanding of reality. I realized that common themes such as addressing how something works facilitate the development of a skill set applicable to special interests in multiple topics. The scientific method serves as a proper base to develop a special interest around any topic in a systematic approach; therefore you can address questions 'like how does something work?' and know where to start and learn how to think. Also, my participation in the Olympiads encouraged me to develop creativity, passion for competition and dedication to science; all of these factors together provide a fruitful beginning in all areas of Medicine and especially research.

My experience in the Olympiads have allowed me first, a new vision of my interests in medical research, like epidemiology, where quantitative analysis is applied to the study of clinical subjects; second, a major dedication to science as evidenced by my constant participation in several research projects; and third, a great commitment to my duties as a doctor-researcher in early development.

Furthermore, my knowledge of Physics has helped me advance in several research projects. For example, we were conducting a study to evaluate a diagnostic test for Chlamydia trachomatis in urine male specimens, comparing a new PCR technique created previously in the laboratory, to two other inmunoenzimatic (EIA) techniques (data not published yet). Because of my background, I was be able to help in the methodology with

Figure 2. Research Group on Infectious Diseases of the Medical Students' Scientific Association of the Universidad del Valle, in Cali, Colombia, ACEMVAL.

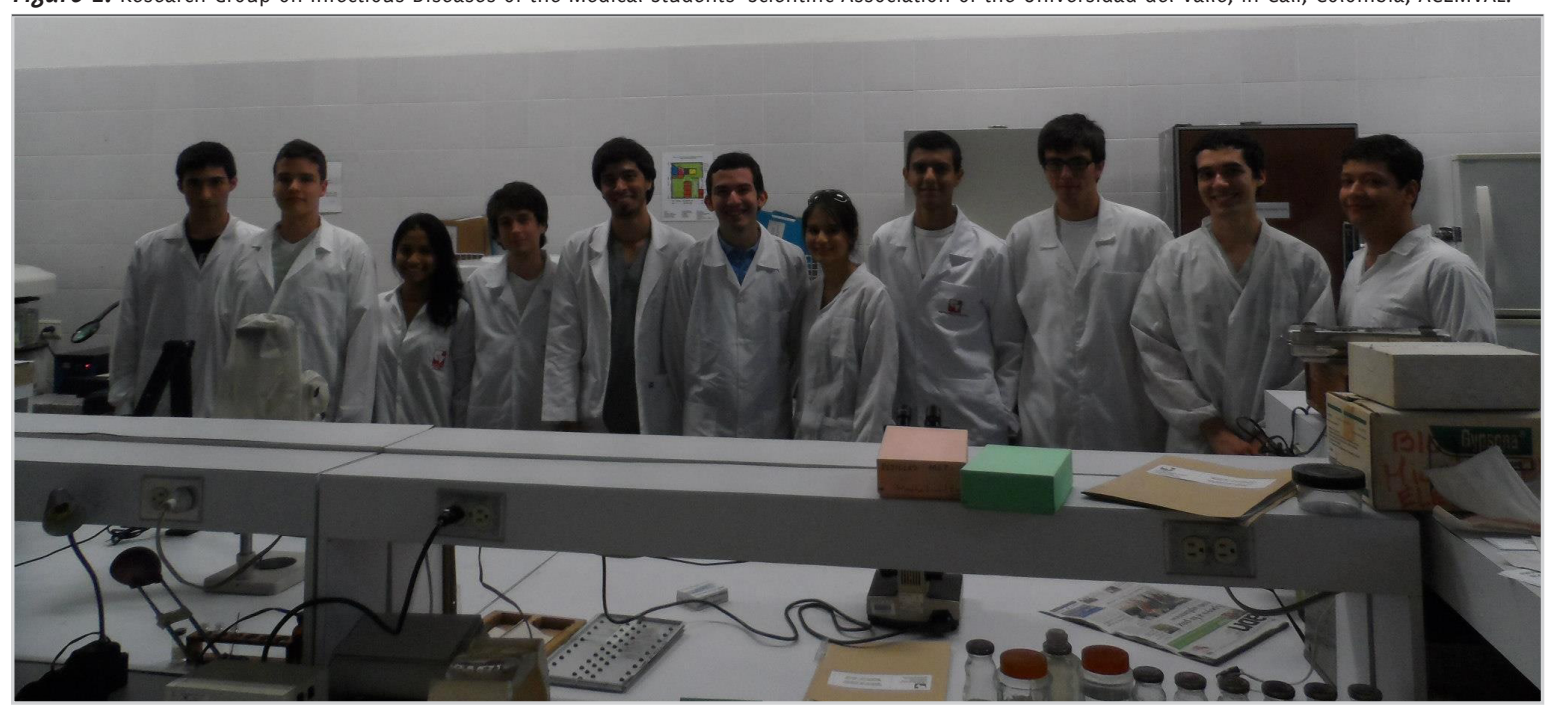


ideas about different statistical models needed to demonstrate possible alterations in the sensitivity and specificity of our PCR due to biologic and socio-demographic factors of the study population. We used ROC curves and other parametric tests to consider the effects of variables such as age, gender, medications (like antibiotics), time elapsed since previous voiding and other urinary tract co-infections, on the diagnostic tests. on another occasion, when our research group was planning a critical article revision on the microbiological effects of local anesthesia, I was able to verify the importance of physical models in the description of bacterial growth and how this growth could be altered by pharmacologic agents. ${ }^{3}$ These are but a few examples of scenarios where I have felt how my skills acquired from Olympiad training have helped me, possibly by facilitating the connection of complex physical models to an artistic science as tangible as medicine.

Summarizing my experience in these events and following progression through my university life in medicine, I want to emphasize the concept that many different life-paths can have a positive effect in medicine, especially in countries where medical education is started immediately after finishing high school. In my case, my experience in the Physics Olympiads have facilitated the development of my early interest in medical investigation, further promoted by interacting with other talented medical students of ACEMVAL (Figure 2). Therefore, it is possible that participation in Olympiads and other competitions are beneficial for the holistic training of medical students.

\section{References}

1. Piaget J. The Origins of Intelligence in Children. 2nd ed. New York: International Universities Press, Inc; 1952.

2. Keevil SF. Physics and medicine: a historical perspective. The Lancet. 2012;379(9825):1517-24.

3. Sakuragi T, Yanagisawa K, Shirai Y, Dan K. Growth of Escherichia coli in propofol, lidocaine, and mixtures of propofol and lidocaine. Acta Anaesthesiol Scand. 1999;43(4):476-9.

\footnotetext{
Acknowledgments

I would like to thank my teachers Fernando Vega, Eduardo Zalamea and Alvaro Ramirez Colonia for all the instruction and training taken before Physics Olympiads.
}

Conflict of Interest Statement â Funding

The Authors have no funding, financial relationships or conflicts of interest to disclose.

Cite as:

Zorrilla-Vaca A. From Physics Olympiads to Medical Research: Lessons Learned. Int J Med Students. 2013;1(3):132-4. 